\title{
Efectos de la Sequía en Bosques y Pastizales del Caribe
}

Resumen: Los problemas de calidad y escasez de agua son preocupantes en el Caribe americano. En años recientes, Puerto Rico y las Islas Vírgenes tuvieron eventos anómalos de clima seco que causaron sequías de moderadas a severas. En 2014-2015, una sequía severa en Puerto Rico requirió la implementación de restricciones de agua que afectaron a millones de personas. El verano del 2015, fue el tercer periodo más seco en Puerto Rico desde el 1898. Nuevos modelos climáticos para la región (Figura 1), proyectan una disminución de la precipitación durante el próximo siglo, mayor variación de las temporadas, y más eventos de precipitación extrema. La distribución espacial y temporal de la lluvia puede tener profundos efectos en la hidrología asá como en la fenología y en el ciclo de vida de los árboles, de los pastizales, y en la incidencia de plagas y los polinizadores. Estos cambios en patrones de lluvia requieren ajustes en cuanto al manejo y al uso de tierras por parte de los productores agrícolas y de los manejadores de recursos naturales y forestales.

Bosques y Pastizales. Puerto Rico y las Islas Vírgenes de Estados Unidos tienen un clima tropical. En su mayoría, los boques están compuestos de árboles siempre verdes de hojas anchas (Figura 2). Son diversos en términos de especies de árboles, con una mezcla de 500 especies nativas e

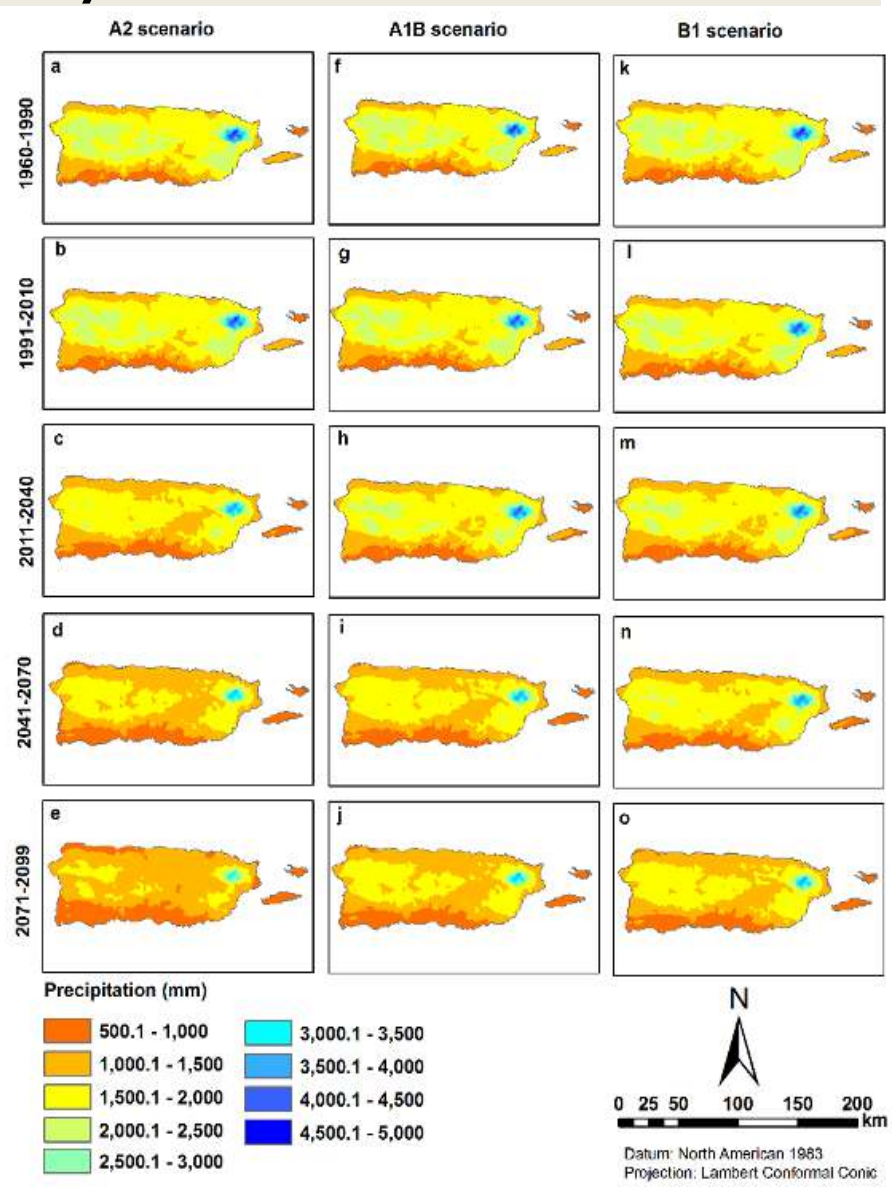
introducidas. Los bosques son importantes por los servicios ecosistémicos que proveen, como la protección de cuencas hidrográficas y de la costa, recreación, hábitats, y mantenimiento de la biodiversidad. Además, los pastizales y los pastos para heno son recursos importantes para la comunidad agrícola.
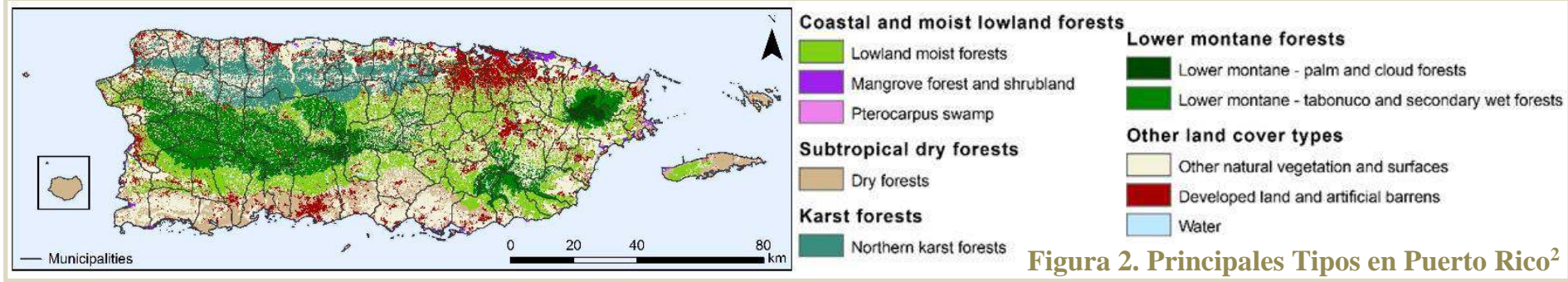

Riesgos y vulnerabilidades de los bosques tropicales: Según el informe del Estado del Clima de Puerto Rico 2010-2013, hay cuatro factores vitales que afectan los principales tipos de bosques en la isla (Figura 3):
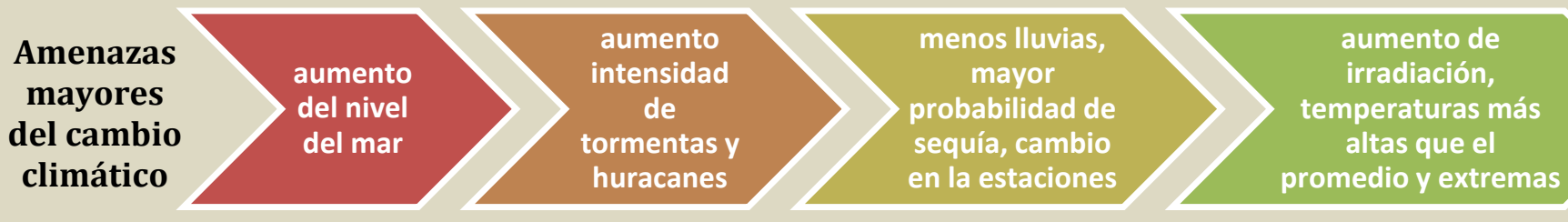
Se prevee que estos factores afecten las zonas de clima, la cobertura forestal y el manejo de tierras agrícolas y forestales. Posibles consecuencias y resultados de estos impactos incluyen ${ }^{2}$ :

- Cambios en la fenología y en el patrón de florecimiento y de producción de frutos en todos los tipos de bosque. Cambios en el establecimiento y sobrevivencia de las semillas puede causar alteraciones en la composición de especies, en su distribución y en abundancia.

- Aumentos en la variabilidad y en la intensidad de tormentas ciclónicas pueden alterar la estructura forestal y las funciones ecológicas de las áreas naturales.

- Mayor riesgo para las comunidades biológicas que viven en extremos de humedad, temperatura, y elevación (bosques nubosos, bosques secos y llanos costeros). Mayor radiación solar, calor, y la condensación de las nubes afectarán las comunidades de bosques en elevaciones más altas.

- Aumento en la intensidad y extensión de las sequías puede ocasionar un aumento en la cantidad y extensión de los incendios forestales y de pastizales.

\section{Efectos de la sequía en los pastizales del Caribe}

La desecación y el estrés por calor reducen el rendimiento de las cosechas, aumentan la mortandad del ganado, de los cultivos, y de los costos en alimentos para animales, en irrigación, agua y energía. En la isla de St. Croix (USVI), la sequía reciente causá la resequedad de la tierra, secá las charcas de agua y causó la muerte de mucho ganado. En Puerto Rico, la falta de lluvia durante los primeros meses del 2014 causó pérdidas en el sector agrícola que se estimaron en \$20 millones de dólares y afectaron a 4,000 agricultores. Más de 2,500 fincas de ganado (28\% de las fincas) sufrieron daños por la sequía; siendo las fincas lecheras y los ranchos de ganado vacuno los más afectados. La falta de lluvia redujo la disponibilidad de heno, la fuente principal de alimento para el ganado vacuno y ovino, ocasionando que los agricultores tuvieran que comprar comida concentrada importada a muy alto precio.

\section{Planificación para adaptación en la agricultura y silvicultura} Los cultivos intercalados y las prácticas agroforestales son estrategias que usan el bióxido de carbono y nitrógeno disponible, a y que moderan la temperatura ambiental y la pérdida de humedad por evapotranspiración. No obstante, hacen falta demostraciones en la región para promover prácticas sostenibles como por ejemplo:

- Usar sistemas silvopastoriles que combinan árboles, forraje y animales. Los árboles son de alto valor maderero y dan sombra para el ganado y forraje, reduciendo el estrés por calor.

- Cambiar las prácticas de cruce de ganado y los sistemas de pastoreo intensivos (sobrepastoreo).

- Modificar facilidades para reducir el estrés por calor en los animales: usar árboles de sombra, añadir ventilación natural y artificial, más sistemas de "neblina" y regaderas.

- Usar razas más tolerantes a la sequía y al calor, como la vaca "pelona" de Puerto Rico o la raza Senepol.

- Diversificar el número de cultivos para resistir a cambios en las temperaturas y de precipitación.

- Desarrollar y usar variedades de alimentos y animales más resistentes a enfermedades y plagas.

- Usar medidas de conservación de agua y humedad del suelo para minimizar daños por falta de agua.

La estabilidad y productividad del sector agrícola y forestal caribeño depende igualmente de factores sociales y económicos que climáticos. Actualmente hay un interés del gobierno y del público en mejorar la industria maderera y forestal como una forma de mejorar la sustentabilidad local, la economía y la calidad de vida.

\section{REFERENCIAS}

1. Henareh Khalyani, A., W. Gould, E. Harmsen, A. Terando, M. Quinones, and J.Collazo, 2015: Climate change implications for tropical islands: Interpolating and interpreting statistically downscaled GCM projections for management and planning. J. Appl. Meteor. Climatol. doi:10.1175/JAMC-D-15-0182.1, in press.

2. Nytch, C, Silander, S, Colon-Rivera, RJ, \& Gould, WA. 2013). Climate Change and Puerto Rico's Forests. In K. R. Jacobs \& E. Diaz Eds.), Puerto Rico's State of the Climate 20102013: Assessing Puerto Rico's Social-Ecological Vulnerabilities in a Changing Climate. (pp. 142-157). 